\begin{tabular}{|c|c|c|c|}
\hline $\begin{array}{c}\text { RESEARCH } \\
\text { ArtiCLE }\end{array}$ & $\begin{array}{r}\text { ADVANCE RESEARC } \\
\text { Volume } 9 \mid \text { Issue } 1\end{array}$ & OCIAL SCIENCE & \\
\hline $0=$ & DOI: 10.15740/HAS/ARJSS/9.1/111-113 & Visit us : www.researchjournal.co.in & \\
\hline
\end{tabular}

\title{
Dizygotic twins: A comparative study on temperament in Bagar and Khadar zones of Haryana
}

Reetu Devi ${ }^{1}$, Bimla Dhanda ${ }^{1}$ and Pinki Rani*

Department of Home Science, FGM Govt. College, Adampur, Hisar (Haryana) India

${ }^{1}$ Department of Human Development and Family Studies, C.C.S. Haryana Agricultural University, Hisar (Haryan) India

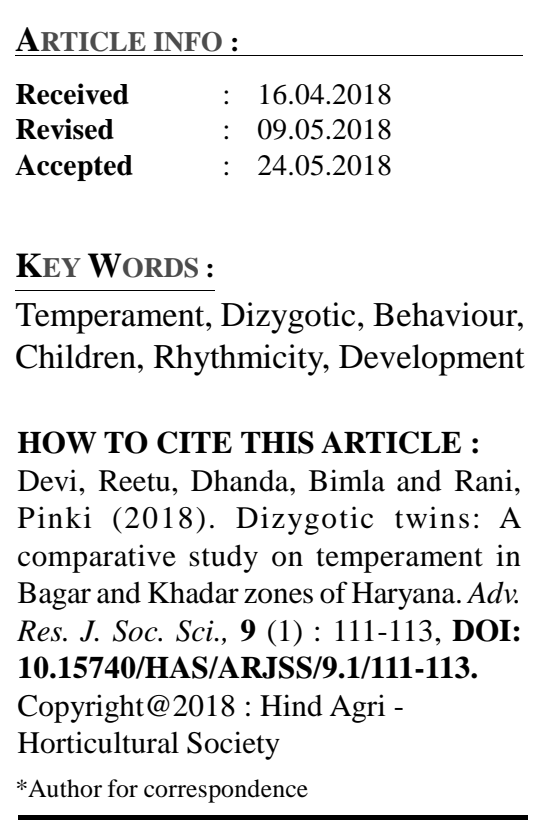

\begin{abstract}
Dizygotic twins are that they develop from two different eggs. Temperament defined as person emotional and behavioural modes of response to environmental events. The present study was conducted in four districts namely; Hisar Fatehabad, Rohtak and Jind of Haryana state with the purpose of availability of maximum numbers of twins in the required age group. A sample of 296 pairs of twins in the age group for the study. Temperament was taken as dependent variable and cultural zone was taken as independent variable. The Malhotra Temperament Schedule (MTS) developed by Malhotra and Malhotra (1988) was used to assess child's temperament. Result revealed that dizygotic twins indicated that highly significant difference were found between bagar and khaddar dizygotic twins on sociability $(2.82 * *)$, emotionality $(4.11 * *)$ and total temperament $\left(3.78^{* *}\right)$ of twins.
\end{abstract}

